\title{
To \\ ECONOMICAL ANALYSIS OF PAVEMENT COMPOSITION USING BENKALMEN BEAM DEFLECTION METHOD
}

\author{
Aditya Agarwal, Deepak Mathur \\ E-Mail Id: ambitiousadi19@gmail.com \\ Department of Civil Engineering, KITE, Jaipur, India
}

\begin{abstract}
Pavement degradation is a major issue in almost every country's road and traffic infrastructure. Bituminous pavement failures can be caused by a variety of factors or a combination of factors. Bituminous pavement failures can be caused by a variety of factors or a combination of factors. Pavement failure happens when an asphalt surface loses its original form and develops material tension, causing problems. Cracking, potholes, depressions, rutting, shoving, upheavals, and travelling are all signs of pavement collapse. This research examines the potential causes of pavement failures and suggests better ways to reduce, if not remove, the causes of bituminous pavement failures. Pavements are complicated structures with many factors to consider, including materials, construction techniques, loads, the environment, maintenance, and economics. As a result, numerous technological and economic factors must be thoroughly understood in order to plan, build, and maintain better pavements. Furthermore, due to the dynamic existence of road pavements, where elements of the pavement are continuously shifting, being added or removed, pavement maintenance problems are still complex. These components deteriorate over time, so keeping them in good working order necessitates a significant investment. In this report, new construction of a section of road overlay or some other preventative measure that is appropriate in terms of technical and financial viability may be included.

The existing project road is consisting of single lane \& intermediate lane and two lane configuration that is to be upgraded to 2 lane with granular shoulders configuration. The entire project road traverses through Barmer, Jalore, Pali districts. The major urban areas through which the project road traverses are Barmer, Rawatsar, Chawa, Sindhari, Sirana, Sayla, Ummedabad, Bishangarh, Sanderao, Falna, Mundara. The proper improvement measures for existing pavement for better performance of project road up to design life depends upon precisely done Pavement Investigations and Condition Surveys. To evaluate the existing pavement condition, various investigations were carried out. The above project case study is part of research area.
\end{abstract}

Keywords: Pavement, Traffic, Road Construction, Environment, Economics.

\section{INTRODUCTION}

The Ministry of Road Transport and Highways owns India's National Highways network, which is a network of trunk roads. The National Highway Authority of India (NHAI), the National Highways and Infrastructure Development Corporation (NHIDCL), and state governments' public works departments (PWDs) build and administer it. The National Highways Authority of India Act of 1988 created the NHAI. The National Highways Authority of India's (NHAI) role, according to Section 16(1) of the Act, is to establish, maintain, and manage the National Highways and any other highways vested in or entrusted to it by the Government of India.

The design procedures for versatile pavements based on CBR values have been defined by the Indian Roads Congress. Pavement designs in the previous version IRC:37-1984 were only good for up to 30 million standard axles of traffic (msa). The previous code is empirical in nature, with applicability and extrapolation limitations. The 2018 version of IRC-37 is the most recent revision.

For the overlay construction Benkelman Beam Deflection (BBD) tests is carried out on the project road in accordance with the guidelines given in IRC: 81, 1997. The deflection data was analyzed to determine the characteristic deflection used for structural evaluation of the pavement. Benkelman Beam devised the simple deflection beam in 1953 for measurement of pavement surface deflection on the WASHO Test Road. It is widely used all over the World for evaluation of the requirements of strengthening of flexible pavements. Deflection beam has been in use in India for more than two decades by different organizations. To lay down a uniform procedure for the design of flexible overlays using the Benkelman Beam deflection technique, tentative guidelines were published by the Indian Roads Congress under the title "Tentative Guidelines for Strengthening of Flexible Road Pavements Using Benkelman Beam Deflection Technique" IRC: 81-1981.

\subsection{Objective of Research work}

The proper improvement measures for existing pavement for better performance of project road up to design life depends upon precisely done upon Pavement Investigations and Condition Surveys. To evaluate the existing pavement condition, various investigations were carried out. The above project case study is part of research area.

$>$ Detection of distress of pavement surface.

DOI Number: https://doi.org/10.30780/IJTRS.V06.I06.001

pg. 1 


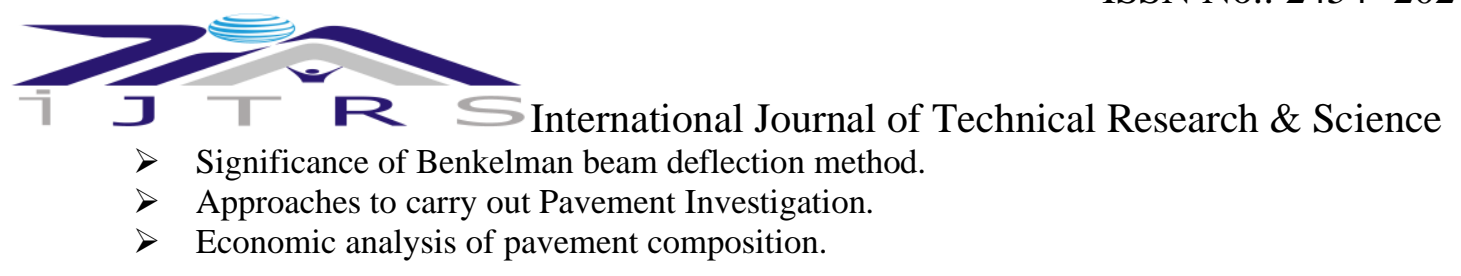

\subsection{Case Study of State Highway-40}

The project road namely Barmer- Sindhari-Jalore Section and Ahore-Bali-Mundara Section is a part of State Highway (SH-40 \& SH-16). The project road is in two sections. First section starts at existing km 1+650 of SH 16 (design chainage Km 0+000) just after junction of NH-68 at Barmer Shaheed circle and ends at design chainage of Km $148+000$ at near Bishangarh. Second section start at existing km 227+700 of SH-16(design CH: 0+000) just after junction of NH-62 \& NH-325 at Sanderao bypass flyover and ends at existing km 254+200 Mundara village in the state of Rajasthan.

The existing project road is consisting of single lane \& intermediate lane and two lane configuration that is to be upgraded to 2 lane with granular shoulders configuration. The entire project road traverses through Barmer, Jalore, Pali districts. For this research State Highway-40 is consider start from Barmer town Ch. 0+000 to Chava village Ch. $27+000$.

\section{LITERATURE REVIEW}

Raina Sachin et al. (2018) ${ }^{[1]}$ Studied Substandard roadway alignment or geometry, lack of shoulders and shoulder defects, absent or inappropriate pedestrian facilities, narrow and defective lanes and bridges/bridge approaches, roadside hazards, and undefined lane widths were among the adverse roadway elements contributing to highway accidents

Naik Ashpaq et al. (2018) ${ }^{[2]}$ Concluded the formation of cracks in the pavement surface causes numerous problems such as discomfort to the users, reduction of safety, etc. In addition to the above, intrusion of water causing reduction of the strength in lower layers as well as lowering of bearing capacity of subgrade soil by pumping of soil particles through the cracks is also a major problem associated with the pavements.

Vaidya O. V. et al. (2018) ${ }^{[3]}$ The Benkelman Beam is used to calculate deflection for the various purposes described above, according to Vaidya O. V. et al. (2018) [3]. Road projects are expensive, and even a small mm error will result in financial losses. This paper explains how the Benkelman beam deflect-meter is used and its specifications in detail. Many articles on this subject will provide you with details on how their project has progressed. This paper will assist you in understanding the characteristics of the Benkelman Beam deflect-meter. This paper includes a comprehensive explanation of how the instrument works, as well as specifications and considerations to consider while using it.

Rohith Sai et al. (2018) ${ }^{[4]}$ From the Benkelman beam deflection technique conducted on the required stretch, the observations obtained are calculated and a design thickness of the overlay required is obtained. Hence overlay thickness of $12 \mathrm{~cm}$ is to be laid on the existing pavement in order to sustain the increasing axle load for future 10 years. Bituminous concrete is to be laid on the existing flexible pavement.

Singh Shashank et al. (2018) ${ }^{[5]}$ To identify type and classification of common defects in flexible pavements. To identify the causes of these defects and suggest remedial measures. To identify the deficiencies in existing pavement maintenance practices. To rectify the identified defects for smooth movement of traffic flow.

Mehta Harshita et al. (2018) ${ }^{[6]}$ It is advisable to implement the necessary maintenance measures at an early stage when the distresses have just started showing up. It is seen that proper pavement measures at an early onset of distresses, can obviate major maintenance expenditure in future. Out of all the deflection measuring methods, the BBD method is the most simple and reliable method. This method is used to measure the rebound deflection of pavement only under static load.

Kumar Pradip et al. (2018) ${ }^{[7]}$ By conducting the Benkelman beam survey deflection has been examine on the existing road stretch. On the basis of this, overlay and maintenance is decided by calculation of PCI index. As per IRC-81 1997 the overlay design thickness is planned on the basis of the above observation.

\section{PAVEMENT EVALUATION METHODOLOGIES}

\subsection{Introduction}

When a building is exposed to loads and different climatic conditions, it will deteriorate over time, so all buildings, including pavements, will deteriorate over time. As a result, these systems, such as pavements in our case, must be assessed on a regular basis to determine their structural state as well as the pavement's remaining life and how much longer the pavement will serve the users satisfactorily. So one should have adequate tools to assess existing pavements, collect some data, collect some information, and be able to analyse the data and make the appropriate decisions in terms of the state of the existing pavement and what should be done with the existing pavement if its life needs to be extended by a certain number of years.

The following techniques will be used in our research to evaluate highway pavement using different approaches.

Pavements are evaluated typically for two types of performance-

DOI Number: https://doi.org/10.30780/IJTRS.V06.I06.001

pg. 2 


\subsubsection{Functional Performance}

The capacity of the pavement to provide a comfortable, clean, and cost-effective riding surface to users is known as functional efficiency. As far as the user is concerned, this is essentially a feature of the pavement; the user needs a safe and comfortable ride. The pavement remains in a technically suitable condition as long as it can provide adequate service to the road user in terms of a safe and comfortable journey.

As long as the pavement is in a position to give satisfactory service to the road user in terms of safe comfortable ride the pavement continues to be in a functionally acceptable condition.

Methods for measures roughness, cracking, and longitudinal slope variance-

$$
\begin{aligned}
& >\quad \text { Present serviceability index (PSI) } \\
& >\quad \text { Roughness } 5^{\text {th }} \text { wheel bump indicator } \\
& >\quad \text { MERLIN roughness index (Old method) }
\end{aligned}
$$

\subsubsection{Structural Performance}

Structural evaluation of pavements which is required to assess the structural soundness of the pavement at a given point of time, which is also required for estimating the remaining life of the pavement and to determine the requirement of rehabilitation that is to calculate overlay thickness if it is required.

Methods for measures destructive or non-destructive evaluation

$>$ Destructive method

$>\quad$ Nondestructive test (NDT)

- Benkelman Beam Deflection Method (BBD)

- Falling Weight Deflection (FWD)

This research is result oriented on make a comparative study between Overlay construction and new construction.

\subsection{Site Location}

The project road namely Barmer- Sindhari-Jalore Section and Ahore-Bali-Mundara Section is a part of State Highway (SH-40 \& SH-16). The project road is in two sections. First section starts at existing km 1+650 of SH 16 (design chainage $\mathrm{Km} \mathrm{0+000)} \mathrm{just} \mathrm{after} \mathrm{junction} \mathrm{of} \mathrm{NH-68} \mathrm{at} \mathrm{Barmer} \mathrm{Shaheed} \mathrm{circle} \mathrm{and} \mathrm{ends} \mathrm{at} \mathrm{design} \mathrm{chainage} \mathrm{of} \mathrm{Km}$ $148+000$ at near Bishangarh. Second section start at existing km 227+700 of SH-16(design CH: 0+000) just after junction of NH-62 \& NH-325 at Sanderao bypass flyover and ends at existing km 254+200 Mundara village in the state of Rajasthan.

The existing project road is consisting of single lane \& intermediate lane and two lane configuration that is to be upgraded to 2 lane with granular shoulders configuration. The entire project road traverses through Barmer, Jalore, Pali districts. The major urban areas through which the project road traverses are Barmer, Rawatsar, Chawa, Sindhari, Sirana, Sayla, Ummedabad, Bishangarh, Sanderao, Falna, Mundara.

The proper improvement measures for existing pavement for better performance of project road up to design life depends upon precisely done Pavement Investigations and Condition Surveys. To evaluate the existing pavement condition, various investigations were carried out. For this research State Highway-40 is consider start from Barmer town Ch. 0+000 to Chava village Ch. 27+000 (Length $27.00 \mathrm{Km}$ ).

\subsection{Deflection Survey by Benkelman Beam}

As per the schedule of concession agreement project road is proposed for reconstruction, raising, strengthening widening, and new construction at various sections. To work out overlay requirement Benkelman Beam Deflection test was carried out. Deflection test of existing pavement was carried out in accordance with the IRC: 81-1997 "Guidelines for Strengthening of Flexible Road Pavements using Benkelman Beam Deflection Technique". The deflection was measured as per CGRA method based on testing under static load. A Truck with a rear axle load of 8.2 tones and a tyre pressure of $5.6 \mathrm{~kg} / \mathrm{sq} . \mathrm{cm}$ was used as the test vehicle for loading purpose.

The extent of rebound deflection of existing pavement under the rear axle was measured at every $50 \mathrm{~m}$ staggered on both side of the carriageway and at a distance of $90 \mathrm{~cm}$ in transverse direction from the carriageway edge. The deflection was measured by the Benkelman Beam consist of a slender beam $3.66 \mathrm{~m}$ long pivoted at a distance of 2.44 $\mathrm{m}$ from the tip. The probe was suitably placed between dual wheels of a loaded truck for measuring rebound and residual deflection of the pavement structure. Guidelines for strengthening of flexible road pavements means we are referring to flexible roads, flexible pavements and these guidelines are meant for Benkelman beam deflection technique.

The pavement performance is closely related to the elastic deflection. Elastic deformation under standard loading conditions depends on various parameters such as the condition of the subgrade, its moisture content, degree of compaction and the condition of various other layers including granule layers, bituminous layers and also it depends upon various climatic conditions like temperature, position of drainage, thickness of various layers, quality of different 


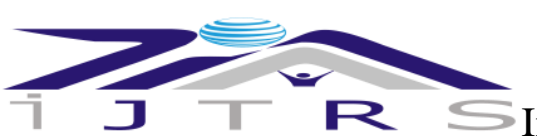

\section{International Journal of Technical Research \& Science}

materials and so on. So all the pavement related parameters affect the elastic deformation of a pavement when it is subjected to wheel loads.

Initially the pavement will be subjected to the load. Then we know what is the reading corresponding to the deflected position of the load. When the load is removed away from the point the pavement rebounds, we will see the reading again and the difference should give us the rebound deflection. That is what we measure in the case of CGRA evaluation procedure. On the other hand, in CGRA procedure initially the load is directly above the point at which we are trying to measure the deflection so the probe point will be here so the dial gauge reading corresponds to the coefficient of the probe point corresponding to the deflected shape. When this load is removed away from the point the pavement surface rebounds and the corresponding absorption of the dial gauge is also made. So what we get here is the rebound deflection.

The Specification of the beam are:

$>$ The length of the beam from hinge to probe point is $2.44 \mathrm{~m}$

$>$ The length of the beam from hinge to dial is $1.22 \mathrm{~m}$

$>$ The distance from the hinge to the front legs is $0.25 \mathrm{~m}$

$>$ The distance from the hinge to the rear legs is $1.66 \mathrm{~m}$

- The lateral spacing of the front legs the spacing between the two front legs is about $0.33 \mathrm{~m}$.

\section{RESULT ANALYSIS}

\subsection{General Description}

Experiment work conducted at site and analysis was done at table. Analysis to be made as per the research objective. To keeping in mind evaluation of pavement theories in what we adopted overlay construction or new construction. Let's find out design criteria for both type of construction

\subsection{Pavement Design New Construction}

The existing project road consists of two lane. The project road has been carrying low volumes of traffic. The condition of the existing pavement is fair to good in major sections and poor to fair some of areas with a view of riding quality. Keeping in view the importance of the project road for the socio economic development of the region and to meet the growing demands of traffic, it is proposed to (i) strengthen the existing two lane road and (ii) widening of single lane and intermediate lane to two lane road with granular shoulders.

Since the existing pavement is of flexible type, it is proposed to design strengthening of the existing pavement with flexible pavements.

Various field surveys and investigations have been carried out to arrive at appropriate inputs for pavement strengthening, pavements for widening of carriageway and overlays design.

\subsubsection{Design Traffic}

The Traffic survey conducted at location mentioned in Schedule-C of concession agreement. The design traffic in million standards axles (MSA) for pavement design for 15 years as per schedule B is determined as mentioned in Table 4.1 As per Classified Volume Count (CVC) the MSA for new pavement design is:

Table-4.1 Classified Volume Count (CVC) MSA for new pavement

\begin{tabular}{|r|c|}
\hline \multicolumn{3}{|c|}{ MSA Calculation } \\
\hline & Description \\
\hline ADT for Design (CVPD) & 462 \\
\hline Distribution factor D & 0.5 \\
\hline VDF(F) & 3.93 \\
\hline $\mathrm{r}$ & $5.00 \%$ \\
\hline $\mathrm{n}$ (Years) & 15 \\
\hline Design N & 2 \\
\hline Construction Period years & $7.15 \mathrm{Msa}$ \\
\hline Design CBR (\%) & $10 \%$ \\
\hline Average Daily Traffic (Present) & 420 \\
\hline Construction Period & 2 Years \\
\hline Annual Growth Factor & $5.00 \%$ \\
\hline Distribution factor & 0.5 \\
\hline Average Daily Traffic (Design) & 462 \\
\hline &
\end{tabular}

\section{DOI Number: https://doi.org/10.30780/IJTRS.V06.I06.001}

pg. 4 


\begin{tabular}{|l|l|l|l|}
\hline l $=$ & 1 & \\
\hline $\mathrm{r}=$ & 0.05 & \\
\hline $\mathrm{n}=$ & 15 & Years \\
\hline $\mathrm{A}=$ & 462 & \\
\hline $\mathrm{D}=$ & 0.5 & \\
\hline
\end{tabular}

$$
N=\frac{365 \times\left[(1+r)^{n}-1\right]}{r} \times A \times D \times F
$$

$$
=7.15 \text { MSA }
$$

\subsubsection{CBR Value}

For determine the CBR value, the standard test procedure has been adopted as per IS 2720 "method of test of soils Laboratory Determination of CBR "mentioned in IRC 37:2001 has been followed.

As per lab test conducted, CBR value found of selected soil of borrow area between 12.05 to $14.45 \%$, however for design purpose CBR value $10 \%$ is considered.

\subsubsection{Pavement Thickness Design Charts}

For the design of new pavement charts are mention in IRC-37:2012. Recommendation for design traffic 1 to 10 MSA is according to IRC plates. The CBR is varies from 12.48 to $13.05 \%$. Thus we consider $10 \%$ CBR for design.

The design charts will give the crust thickness of the pavement for the above outcomes. The total thickness consists of granular subbase, base and bituminous surface. The individual layers are designed based on PLATE-7 as described IRC-37-2012.

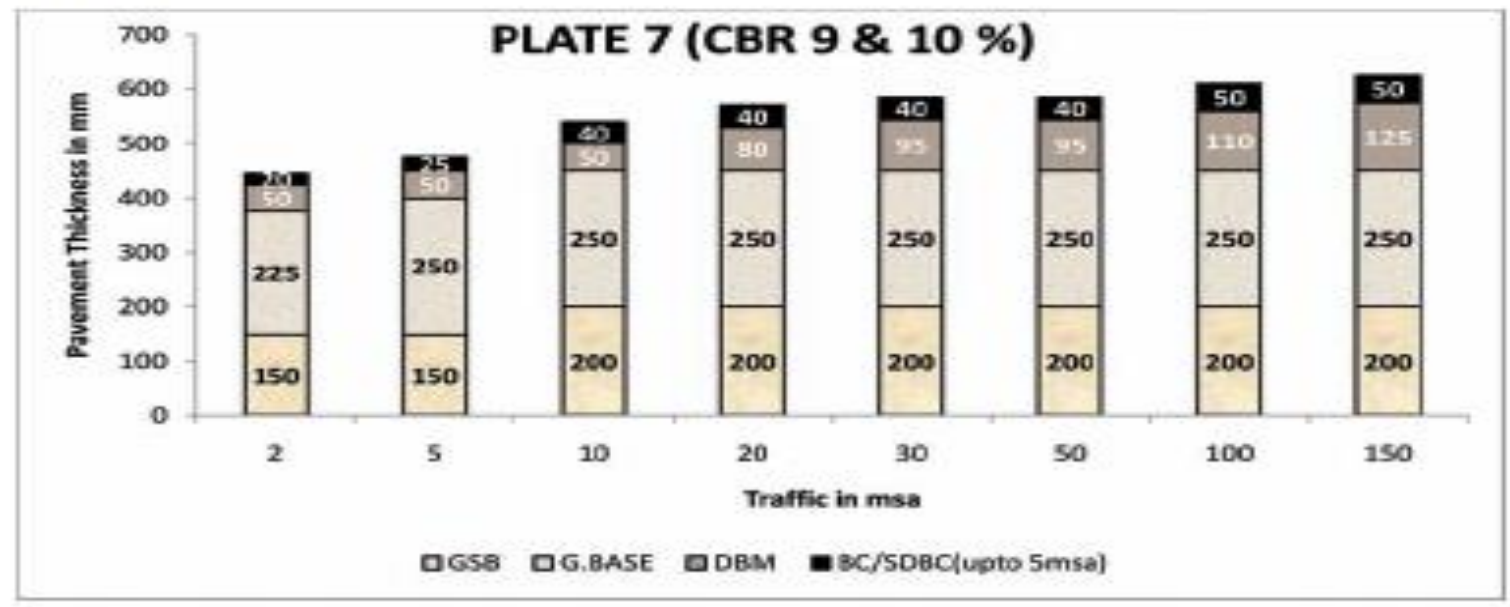

Fig. 4.1 IRC-37-2012

Table-4.2 Types of layer \& pavement composition

\begin{tabular}{|c|l|c|}
\hline \multirow{2}{*}{ Sr. No } & \multicolumn{1}{|c|}{ Type of Layer } & Pavement Composition \\
\hline 1 & Bituminous layer(Wearing course) & 40 \\
\hline 2 & Bituminous layer(Binder course) & 50 \\
\hline 3 & Granular Base layer & 250 \\
\hline 4 & Granular Sub Base layer & 200 \\
\hline 5 & Total thickness & 540 \\
\hline
\end{tabular}

\subsection{Pavement Design Overlay Construction}

It is necessary to evaluate the condition of the existing pavement in terms of its functional and or structural condition periodically. Some agencies carry out only the function evaluation, some agencies carried only the structural evaluation but there are agencies which carry out that carry out both the functional evaluation and structural evaluation

DOI Number: https://doi.org/10.30780/IJTRS.V06.I06.001

pg. 5 


\section{ᄀ $\mathrm{R} S$ International Journal of Technical Research \& Science}

and evaluate the pavement in terms of its capability provide proper functional performance and also proper structural performance.

Overlay is that reinforcing layer that would provide over an existing pavement. This is because pavements that do not have adequate structural strength to carry the projected future traffic will have to be reinforced by providing additional pavement layer.

So once it is to assess the condition of the existing pavement and also in terms of the subgrade strength then using the criteria we can assess whether this pavement is capable of carrying more loads or not and we can also assess how many more loads it can carry so this is what we call as remaining life. And on the basis of assessing the remaining life of the pavement

We can calculate the requirement for additional reinforcing layer as depicted here. So in this case the need for reinforcing was felt so the overlay that is provided is depicted here.

\subsubsection{Benkelman Beam Deflection Test}

Entire project road section in Barmer to Chava, Benkelman beam deflection test has been carried out.

Benkelman Beam Deflection (BBD) tests are carried out on the project road in accordance with the guidelines given in IRC: 81,1997 . The deflection data was analyzed to determine the characteristic deflection used for structural evaluation of the pavement. The BBD data analysis is given in this report above.

Table-4.3 Deflection test summary

\begin{tabular}{|c|c|c|c|c|}
\hline \multirow{2}{*}{ Sr. No. } & \multirow{2}{*}{ Name of Road } & \multicolumn{2}{|c|}{ Chainage } & \multirow{2}{*}{ Characteristic Deflection(mm) } \\
\hline & & From & To & \\
\hline 1 & SH-40 & $0+000$ & $1+000$ & 1.36 \\
\hline 2 & SH-40 & $1+000$ & $2+000$ & 1.38 \\
\hline 3 & SH-40 & $2+000$ & $3+000$ & 1.37 \\
\hline 4 & SH-40 & $3+000$ & $4+000$ & 1.38 \\
\hline 5 & SH-40 & $4+000$ & $5+000$ & 1.38 \\
\hline 6 & SH-40 & $5+000$ & $6+000$ & 1.35 \\
\hline 7 & SH-40 & $6+000$ & $7+000$ & 1.37 \\
\hline 8 & SH-40 & $7+000$ & $8+000$ & 1.37 \\
\hline 9 & SH-40 & $8+000$ & $9+000$ & 1.36 \\
\hline 10 & SH-40 & $9+000$ & $10+000$ & 1.36 \\
\hline 11 & SH-40 & $10+000$ & $11+000$ & 1.35 \\
\hline 12 & SH-40 & $11+000$ & $12+000$ & 1.37 \\
\hline 13 & SH-40 & $12+000$ & $13+000$ & 1.40 \\
\hline 14 & SH-40 & $13+000$ & $14+000$ & 1.38 \\
\hline 15 & SH-40 & $14+000$ & $15+000$ & 1.38 \\
\hline 16 & SH-40 & $15+000$ & $16+000$ & 1.34 \\
\hline 17 & SH-40 & $16+000$ & $17+000$ & 1.38 \\
\hline 18 & SH-40 & $17+000$ & $18+000$ & 1.37 \\
\hline 19 & SH-40 & $18+000$ & $19+000$ & 1.36 \\
\hline 20 & SH-40 & $19+000$ & $20+000$ & 1.38 \\
\hline 21 & SH-40 & $20+000$ & $21+000$ & 1.35 \\
\hline 22 & SH-40 & $21+000$ & $22+000$ & 1.40 \\
\hline 23 & SH-40 & $22+000$ & $23+000$ & 1.38 \\
\hline 24 & SH-40 & $23+000$ & $24+000$ & 1.35 \\
\hline 25 & SH-40 & $24+000$ & $25+000$ & 1.34 \\
\hline 26 & SH-40 & $25+000$ & $26+000$ & 1.40 \\
\hline 27 & SH-40 & $26+000$ & $27+000$ & 1.40 \\
\hline
\end{tabular}

DOI Number: https://doi.org/10.30780/IJTRS.V06.I06.001

pg. 6 


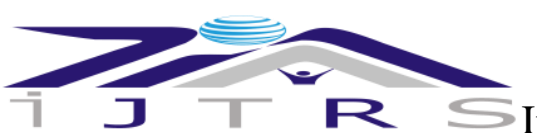

\section{International Journal of Technical Research \& Science}

Overlay thickness has been worked out based on the characteristic deflection obtained by the BBD analysis as shown in table and the design traffic for each section for 15 years design period given in table. The requirement of overlay is obtained from chart shown in Figure in terms of bituminous macadam. The same has been converted into Bituminous Concrete (BC) and Dense Bituminous macadam (DBM) by multiplying with equivalency factor as given in IRC $81-$ 1997.

Bituminous macadam may not be used. Obviously bituminous macadam cannot be used for surface so this has to be replaced by the total beam requirement that has to provide in terms of DBM, also it can be BM, BM, BBM, BC or other types of bituminous layers. So using the conversion factors that are given here we can convert the total requirement of $\mathrm{BM}$ into different component layers.

For example, BM can be converted into other materials using equivalence factors that is $1 \mathrm{BM}=1.5 \mathrm{WBM}$ or bituminous macadam or built up spray grout layer if you are going to replace some requirement of BM in terms of WBM, WMM or built up spray grout. Alternatively if you are trying to replace BM in terms of DBM AC or BC bituminous concrete or semi dense concrete equivalence is $1 \mathrm{BM}=0.7 \mathrm{DBM}, \mathrm{AC}$ or SDC.

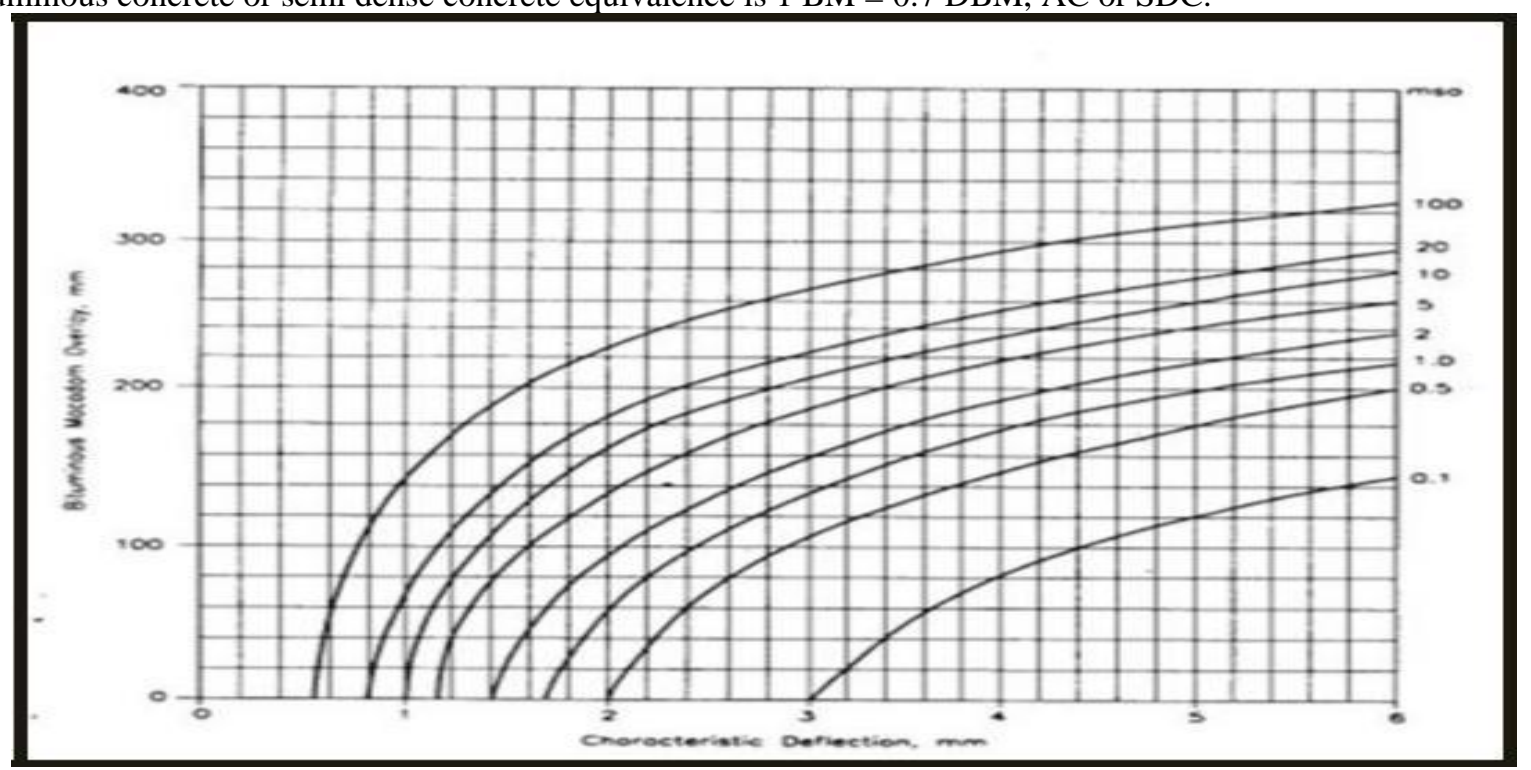

Fig. 4.2 Overlay Thickness for $1.40 \mathrm{~mm}$ deflection and 10 MSA

The composition of overlay is based above calculation is as follows:

Table-4.4 Pavement deflection data

\begin{tabular}{|c|c|c|c|c|c|c|c|c|c|}
\hline \multirow{2}{*}{$\begin{array}{c}\text { Sr } \\
\text { no. }\end{array}$} & \multicolumn{2}{|c|}{ CH: } & $\begin{array}{c}\text { Characteristic } \\
\text { Deflection (mm) } \\
\text { Max. }\end{array}$ & $\begin{array}{c}\text { Visual } \\
\text { Condition }\end{array}$ & MSA & $\begin{array}{c}\text { BM } \\
\text { Req. }\end{array}$ & BC & DBM & $\begin{array}{c}\text { Provided } \\
\text { in BM }\end{array}$ \\
\cline { 2 - 8 } & From & To & \multicolumn{7}{|c|}{ BARMER TO CHAVA Stretch } \\
\hline 1 & $0+000$ & $27+000$ & 1.40 & Good & 7.15 & 110 & 40 & 50 & $\mathbf{1 2 9}$ \\
\hline
\end{tabular}

As pre equivalence factor we provided

Table 4.5 Overlay design

\begin{tabular}{|c|c|c|c|}
\hline Item & \multicolumn{2}{|c|}{ Thickness (mm) } & Remarks \\
\hline BM Required & \multicolumn{2}{|c|}{110} & \\
\hline Provided in BM & 129 & $\begin{array}{c}\text { BC- } 40 \\
\text { DBM-50 }\end{array}$ & $\begin{array}{l}\text { BC, DBM adapted as per IRC } 37- \\
2012 \text { (plate- } 8 \text { ), that is } 0.7(90) \text { of } 129 \\
\text { because of min thickness of BC } 40 \text { is } \\
\text { compulsory. }\end{array}$ \\
\hline
\end{tabular}

\subsection{Cost Analysis}

For financial viability the cost analysis to be done, the cost analysis is as follows-

\subsubsection{Cost for New Construction}

For new construction cost following layers to be considered-

BC -40

DOI Number: https://doi.org/10.30780/IJTRS.V06.I06.001

pg. 7 
DBM-50
WMM-25

GSB-200

Subgrade-500

The detailed cost analysis for new construction is as follows:

Table- 4.6New construction

\begin{tabular}{|c|c|c|c|c|c|c|c|c|c|}
\hline $\begin{array}{c}\text { Item } \\
\text { No. } \\
\end{array}$ & Item & Unit & No. & Length & Breadth & Height & Quantity & $\begin{array}{l}\text { Rate } \\
\text { (Rs.) }\end{array}$ & Amount (Rs.) \\
\hline 1 & Subgrade & Cum & & & & & $1,83,330.00$ & 223.00 & $4,08,82,590.00$ \\
\hline \multirow[t]{4}{*}{2} & GSB & & & & & & & & \\
\hline & LHS & Cum & 1.00 & $23,000.00$ & 6.88 & 0.20 & $31,648.00$ & 891.00 & 2,81,98,368 \\
\hline & RHS & Cum & 1.00 & $23,000.00$ & 6.88 & 0.20 & $31,648.00$ & 891.00 & $2,81,98,368$ \\
\hline & $\begin{array}{l}\text { Granular } \\
\text { shoulders }\end{array}$ & Cum & 2.00 & $23,000.00$ & 2.50 & 0.15 & $17,250.00$ & 891.00 & $\mathbf{1 , 5 3 , 6 9 , 7 5 0}$ \\
\hline \multirow[t]{3}{*}{3} & WMM & & & & & & & & \\
\hline & LHS & Cum & 1.00 & $23,000.00$ & 3.80 & 0.25 & $21,850.00$ & $1,219.00$ & $2,66,35,150.00$ \\
\hline & RHS & Cum & 1.00 & $23,000.00$ & 3.80 & 0.25 & $21,850.00$ & $1,219.00$ & $2,66,35,150.00$ \\
\hline \multirow[t]{2}{*}{4} & Primer Coat & & & & & & & & \\
\hline & & Sqm & 1.00 & $23,000.00$ & 7.60 & - & $1,74,800.00$ & 31.00 & $54,18,800.00$ \\
\hline \multirow[t]{2}{*}{5} & Tack Coat & & & & & & & & \\
\hline & & Sqm. & 1.00 & $23,000.00$ & 7.00 & - & $1,61,000.00$ & 8.00 & $12,88,000.00$ \\
\hline \multirow[t]{4}{*}{6} & DBM & & & & & & & & \\
\hline & $\begin{array}{l}\text { New } \\
\text { Construction }\end{array}$ & & & & & & & & \\
\hline & LHS & Cum & 1.00 & $23,000.00$ & 3.50 & 0.050 & $4,025.00$ & $5,910.00$ & $2,37,87,750.00$ \\
\hline & RHS & Cum & 1.00 & $23,000.00$ & 3.50 & 0.050 & $4,025.00$ & $5,910.00$ & 2,37,87,750.00 \\
\hline \multirow[t]{5}{*}{7} & BC & & & & & & & & \\
\hline & $\begin{array}{l}\text { BC New } \\
\text { Construction }\end{array}$ & 0 & - & - & - & - & - & - & - \\
\hline & LHS & Cum & 1.00 & $23,000.00$ & 3.50 & 0.04 & $3,220.00$ & $6,815.00$ & $2,19,44,300.00$ \\
\hline & RHS & Cum & 1.00 & $23,000.00$ & 3.50 & 0.04 & $3,220.00$ & $6,815.00$ & $2,19,44,300.00$ \\
\hline & & & & & & & \multicolumn{2}{|c|}{ Grand Total } & Rs. $26,40,90,276.00$ \\
\hline
\end{tabular}

\subsubsection{Cost for Overlay Construction}

For Overlay Consider layers are:

BC-40

DBM-50

Table-4.7 Overlay construction

\begin{tabular}{|c|c|c|c|c|c|c|c|c|c|}
\hline $\begin{array}{c}\text { Item } \\
\text { No. }\end{array}$ & Item & Unit & No. & Length & Breadth & Height & Quantity & $\begin{array}{c}\text { Rate } \\
\text { (Rs.) }\end{array}$ & Amount (Rs.) \\
\hline 1 & $\begin{array}{c}\text { Primer } \\
\text { Coat }\end{array}$ & Sqm & 1.00 & $23,000.00$ & 7.60 & - & $1,74,800.00$ & 31.00 & $\mathbf{5 4 , 1 8 , 8 0 0 . 0 0}$ \\
\hline
\end{tabular}

DOI Number: https://doi.org/10.30780/IJTRS.V06.I06.001

pg. 8 


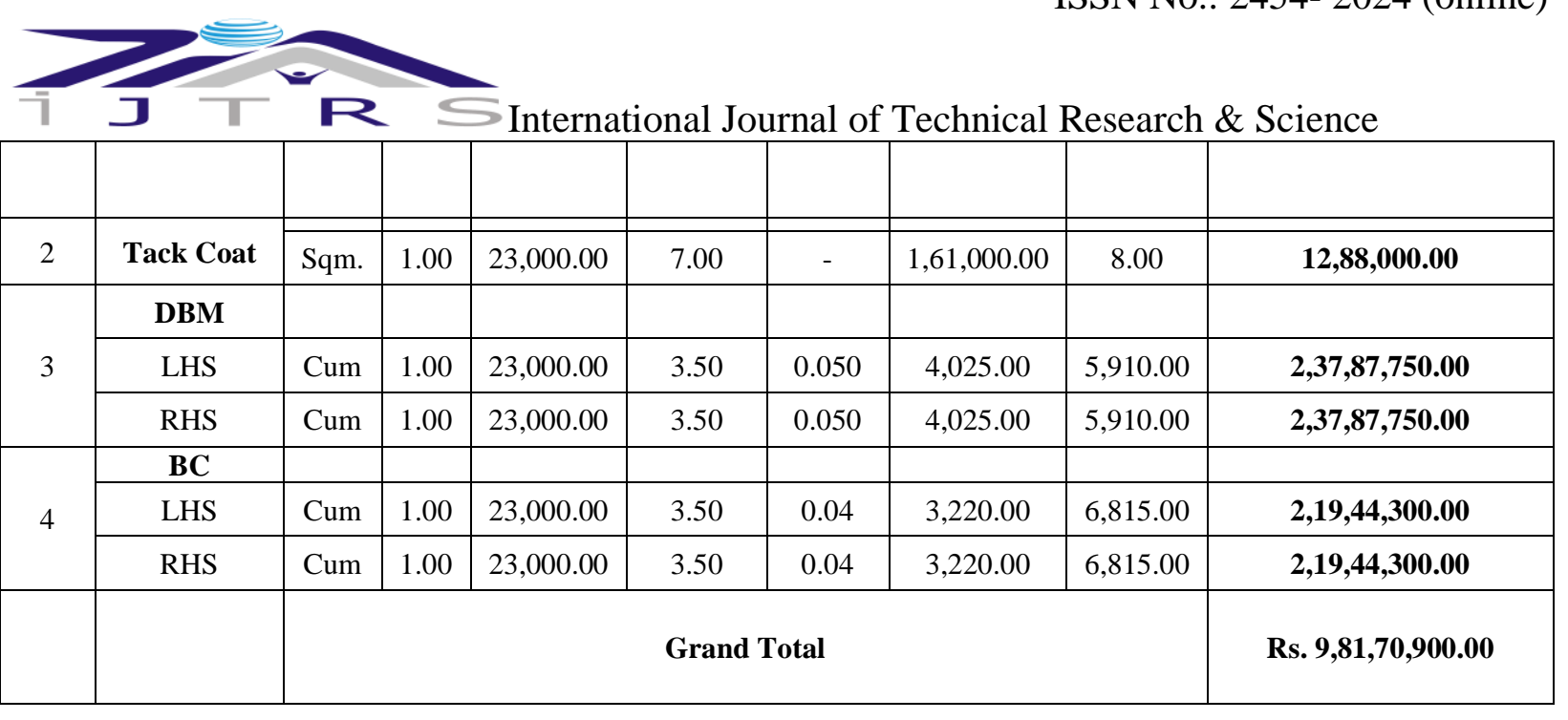

\section{CONCLUSION}

The work is started with some result oriented objectives. After considering literature review around the research area we taken about idea for implementing the research. According to methodology and codal provision various test has been carried out. From the various test results we find out criteria for both type of construction i.e for overlay and new construction. The ex. layers of road have enough structural strength to sustain the traffic. We could proposed and recommend overlay construction for that kind of road, it is technically and finically viable for this type of project and its increases life span of road.

Here given below following Conclusion obtained from research-

$>$ From visual condition survey it has been observed that no such serious distress has been found and $81 \%$ of pavement condition is good.

$>$ Deflection test Benkelman beam is carried out and max. Characteristic Deflection is $1.40 \mathrm{~mm}$.

$>$ The difference of cost amount between new construction and overlay construction is around 16 Crore.

$>$ Overlay construction is beneficial from new construction financially \& technically.

\section{FUTURE SCOPE}

Despite the fact that the given analyses and methodologies are very good and serve as good relative criteria for the design and economic analysis of pavement based on deflection criteria, there are still some areas where improvements can be made. In this sense, we'll look at some of the outcomes that could be changed or expanded upon. The following points should be considered for future research.

$>$ To conduct functional and structural evaluation of the pavement sections in respect of sustainability of the concerned pavements.

$>$ To establish relationships of pavement deterioration with traffic growth with due consideration of independent variables/parameters.

$>$ Comparative Studies between Benkelman Beam Deflections (BBD) and Falling Weight Deflect meter (FWD) Test for Flexible Road Pavement

$>$ Development of a model for Pavement Characteristic Deflection

$>$ Use of the Benkelman Beam in Design and Construction of Highways

\section{REFERENCES}

[1] Raina S. Dangar, DR. L.B.Zala, DR. F.S.Umrigar (2018), Pavement Deterioration 'A Case Study On National Highway 8b Section Rajkot-Bamanbore (Km 185/0- Km 216/8)' .

[2] Naik A. Adlinge, Prof. A.K. Gupta (2018) Pavement Deterioration and its Causes.

[3] Vaidya O.V. Anand Kumar, Avinash Kumar Patel (2018) Pavement Condition Survey; A Compendium Of Distresses On NH 12 - Kota -Jhalawar India.

[4] Rohith. Subramanyam, Aravind S, Prasanna Kumar R (2018). Functional and Structural Evaluation of a Road Pavement.

[5] Singh S, Dr. S. S. Pimplikar (2018) A Comparative Study on Pavement Condition Rating Methods for Flexible Roads.

[6] Mehta H, P. P. Nagrale (2018) Defining Pavement Condition States to Quantify Road Quality for Designing of Pavement Maintenance Management System.

[7] Pradip K. Dr. Rakesh Gupta (2018). Defects in Flexible Pavement and its Maintenance.

[8] Razak Deepu (2018). Bituminous Pavement Failures.

DOI Number: https://doi.org/10.30780/IJTRS.V06.I06.001

pg. 9 
I - R $S$ International Journal of Technical Research \& Science

[9] Khan S., Dr. Rakesh Gupta (2017). Study of defects in flexible pavement and its maintenance.

[10] V. Aghera, Dr. Devinder Sharma, Kumar (2017). A Review Paper On Strengthening And Widening Of Flexible Pavement: A Case Study Of Kaithal-Rajasthan Border (Nh-152/65).

[11] Gupta R., Mr. Abhijeet Kishore, Avinesh (2017). Study on Widening and Strengthening of Existing National Highway No - 21 (Kurali - Kiratpur Section) in the State of Punjab in India.

[12] Bin Rashid, Ngangbam Bulbul Singh, Pebam Rocky Singh, Dr.Yendrembam Arunkumar Singh (2017) Strengthening Of Existing Four Lane Flexible Pavement On NH 150 Malom To Moirang Lamkhai Section - A Case Study.

[13] Joyshree, Dr.Mohammad Shafi Mir, Tanzeel Rashid (2017). Evaluation And Strengthening Of Reconstructed Roads Excavated For Utilities Using Benkelman Beam Deflection (Bbd) Technique (A Case Study).

[14] Tariq Mohd, Hemant Kumar Agrawal (2017) A study about the widening and strengthening of existing national highways in India.

[15] Hardik V. Aghera, Jyoti Mandhani, Ravindra V. Solanki (2017). A Review on Performance Evaluation of Flexible Pavement.

[16] Shemyla Khan, Ajit Singh (2017). Deterioration of Rural Road Pavement Caused by Heavy Vehicular Traffic, A Case Study of Wanpora Road.

[17] Shubham (2017) Functional Evaluation and Overlay Design of Existing Flexible Pavement: A Case Study of Karni \& Khara Industrial Area Road in Bikaner.

[18] Pradip kumar Dinesh bhai Patel, Prof. Parth D.Patel (2017). Structural Evaluation of Flexible Pavement by Benkelman Beam of State Highway-133of (K-7toVavol).

[19] Ghosh, Prof. Srinath Karli, Vaibhav K. Solanki (2017) Comparative Studies between Benkelman Beam Deflections (BBD) and Falling Weight Deflect meter (FWD) Test for Flexible Road Pavement.

[20] Shashank Raj Singh, Satya, Shubham Upadhyay (2017). Flexible Pavement in highway Engineering

[21] Akshay Gadiya, Sagar Bhor, Parimal Parchure, Ankkit Bafna (2017) Evaluation of Rigid Pavements By Deflection Approach.

[22] Prof. A.A.Patel Dhaval V. Lad (2017) Pavement Evaluation by Benkelman Beam of State Highway Section (Waghodiya Crossing to Limda).

[23] Prof. O. V. Vaidya, Shubham Dighole, Jahabaj Pathan, Vicky Kankariya (2016) Working of Benkleman Beam Deflectometer.

[24] Sai Rohith, M Vishnu Vardhan, B G Rahu3, Dola Sanjay (2016) Pavement Design Using Benkelman Beam Method.

[25] Dr. Umesh Sharma, Non-Destructive Evaluation of an Internal Road of Chandigarh - A Critical Study.

[26] Dipen J. Patel, Prof. Amit A. Amin (2016). Functional Evaluation and Overlay Design of Flexible Pavement: A Case Study of Thasra -Hadmatiya Road.

[27] Mahendrakar Kiran Kumar, D.Gouse Peera, Konge Praveen Kumar (2016). A Study on Overlay Design of Repeatedly Deteriorating Flexible Pavement.

[28] Rabindranath Ghosh, Upvan Kunmar, Shubham Gupta, Vivek Kumar, Azharuddin Malik (2015). A Review Paper on Bituminous Concrete Mixed Design for Road Construction.

[29] D. R. Jundhare, Dr. K. C. Khare; and Dr. R. K. Jain (2015). Development Correlation between Benkelman Beam Deflection and Falling Weight Deflectometer for Conventional White topping Overly.

[30] Mr. Nikesh D. Bele (2015). Design of Flexible and Rigid Pavement: A Review.

[31] A. M. Admute, A. V. Gandhi , S. S. Adsul, A. A. Agarkar, G. S. Bhor , G. P. Kolte (2015). Permeable Pavements: New Technique for Construction of Road Pavements in India.

[32] Sachin Raina, Dr. Rakesh Gupta (2015) Review Paper on Study on Strengthening and Drainage Of Flexible Pavements.

[33] Ashpaq Majeed Naik, Dr. Rakesh Gupta (2015). A Review Paper on Evaluation of Flexible Pavement Failures.

[34] Milind V. Mohod, Dr. K. N.Kadam (2015). A Comparative Study on Rigid and Flexible Pavement: A Review.

[35] Bhrugu Kotak, Parth Zala, Abhijitsinh Parmar (2015). Design of Flexible Pavement: A Case Study of OMGC To Venus, Bhoyan Rathod.

[36] Er. Devendra Kumar Choudhary1, Dr. Y. P Joshi (2014) A Detailed Study of CBR Method for Flexible Pavement Design.

[37] Dr. S.N. Sachdeva, Ravinder Kumar (2014) Traffic Analysis and Design of Flexible Pavement With Cemented Base and Subbase.

[38] Mr Sandeep D. Khorasiya (2014). Comparative Study of Flexible Pavement Design: a Case Study of Bhavnagar - Dholera Highway (Nh-8E) in Gujarat, India

[39] Patel Rinkan, Bhatt Khushbu, N.B.Parmar (2014) Literature Review On Development Of Flexible Pavement Condition Index For Highway. 
7 J $\mathrm{R} S$ International Journal of Technical Research \& Science

[40] Saurabh Jain, Dr. Y. P. Joshi, S. S. Goliya (2013) Design of Rigid and Flexible Pavements by Various Methods \& Their Cost Analysis of Each Method.

[41] Khorasiya Sandeep D. (2013). Flexible Pavement in highway Engineering.

[42] Jain Saurabh, Sagar Bhor, Parimal Parchure, Ankkit Bafna (2013) Evaluation of Rigid Pavements By Deflection Approach.

[43] R. Vasudevan (2011) Pavement Evaluation by Benkelman Beam of State Highway Section (Waghodiya Crossing to Limda).

[44] Esmaeil, Shubham Dighole, Jahabaj Pathan, Vicky Kankariya (2011) Working Of Benkleman Beam Deflectometer. 